\title{
Novel Use of a Hemostatic Dressing in the Management of a Bleeding Leech Bite: A Case Report and Review of the Literature
}

\author{
Preston J. Fedor, MD \\ From the University of Texas Southwestern, Department of Surgery (Emergency Medicine), Section on EMS, Disaster Medicine, and \\ Homeland Security, Dallas, TX.
}

\begin{abstract}
Persistent bleeding from leech bites is a common occurrence, although little evidence is available to guide management. Detailed here is the case of a 30-year-old American man who presented with two leech bites after a trek through the jungle in Nepal, one of which continued to briskly ooze blood despite standard wound care. The wound was ultimately treated with QuikClot gauze, which allowed for rapid hemostasis without rebleeding. This case report describes the first use of a hemostatic dressing for this purpose, and reviews what is known about hemostatic agents and about leeches in order to discuss how they make us bleed and what to do when a leech bite occurs.
\end{abstract}

Key words: leeches, ectoparasitic infestations, bleeding, blood coagulation, hemostatic techniques, bandages

\section{Introduction}

Leeches have been used for medicinal purposes since the time of Hippocrates, although they have been plaguing mankind throughout our history. A painting found in an Egyptian tomb shows the first recorded leech bite back in 1500 BCE. Leeches are even mentioned in the Bible and in the Koran. ${ }^{1,2}$

Leeches are segmented invertebrates closely related to earthworms, belonging to the phylum Annelida and the class Hirudinae. They enjoy a worldwide distribution, are most common in tropical areas, and are found in marine, freshwater, and terrestrial environments. Of the 600-plus species of leeches, only a minority actually feed on blood (sanguivores). The blood feeding, which is done with a set of biting jaws near the leech's anterior sucker, leave a Y-shaped wound behind. ${ }^{3}$ Not only do the leeches ingest a significant amount of blood for their

A brief summary of this case was presented as a photo case poster at the SAEM meeting, June 2011, Boston, MA.

Disclaimer: The author has no financial interests in any of the products discussed in this report.

Corresponding author: Preston J. Fedor, MD, University of Texas Southwestern, Division of Emergency Medicine, 5323 Harry Hines Blvd, MC 8579, Dallas, TX 75390-8579 (e-mail: prestonjfedor@ gmail.com). body weight, but also the wound itself can continue to bleed for hours to days. ${ }^{4}$

Even though leech bites are a common affliction in certain parts of the world, there is virtually no research on methods to manage persistently bleeding wounds. This novel case demonstrates successful use of a hemostatic dressing to stop bleeding from a presumed leech bite. Additionally, leech and hemostatic dressing literatures are reviewed in the context of wilderness medicine.

\section{Case Presentation}

The University of New Mexico's department of emergency medicine teaches an annual month-long global health course in Nepal for residents and medical students. ${ }^{5}$ After a jungle trek in Chitwan National Park, one of the emergency medicine residents, a 30-year-old Caucasian man, came to the dinner table with a bloody sock in his hand. While changing clothes, he had noted a bleeding wound on his right ankle that had soaked through his sock and coated the inside of his hiking boot in blood. A leech bite was immediately presumed, but no offending creature could be located initially. Despite thorough wound cleansing and two 10-minute attempts at direct pressure and elevation, the lesion continued to ooze significantly (Figure 1). 


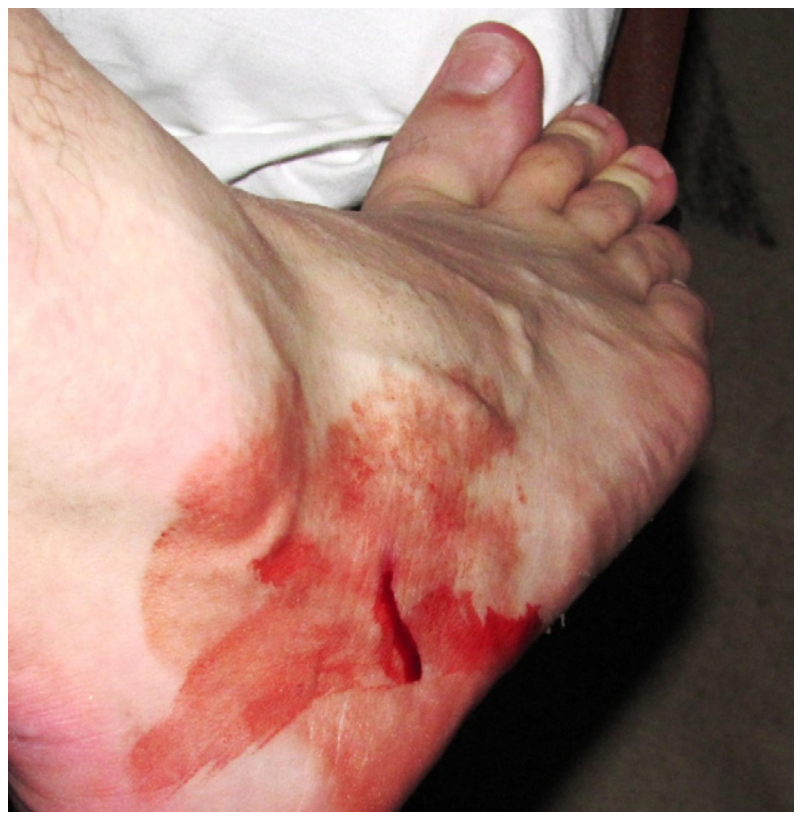

Figure 1. Oozing leech bite immediately after direct pressure removed.

The time the bite occurred and how long the leech was attached were unknown, as the patient had spent the previous 5 to 6 hours hiking through the jungle. He denied feeling any pain during the hike. Anticipating leech activity, he had tucked his pant legs into his tight hiking socks, and sprayed both ankles with insect repellant. Coincidentally, immediately after the hike, he noted that a large portion of his left pant leg was covered in blood at knee level, below which was a clotted leech bite. That leech was found crawling away.

On examination, a $5 \times 5 \mathrm{~mm}$ circular lesion was noted just inferior to the lateral malleolus of the right ankle. The lesion was briskly bleeding over an excoriated and erythematous base, with a Y-shaped lesion in the center (Figure 2). The area was nontender and had no surrounding erythema. One additional lesion was noted on the left lateral thigh, the same size as the first, and coated with dried blood.

The patient appeared otherwise well, and had no evidence of other bleeding or bruising. He had no other complaints or systemic symptoms, had no other medical problems, took no medications, and had no allergies. He had no known personal or family history of bleeding or clotting disorders. Malaria prophylaxis was not taken by the group, nor did the patient exhibit any malarial symptoms. No laboratories were available in the jungle of Nepal.

After an additional attempt at elevation and firm direct pressure for 10 more minutes, the right ankle wound continued to ooze. The patient located a Quik-
Clot (Z-Medica Corp, Wallingford, CT) hemostatic dressing (gauze impregnated with the oxides of sodium, silicon, aluminum, and magnesium, mixed with a small amount of quartz and kaolin) in his personal first aid kit. He folded the $4 \times 4$ inch gauze into a 1-inch square, held direct pressure briefly, and then taped it tightly over the wound. No additional blood was noted to soak through or around the dressing. Approximately 15 minutes later, the dressing was removed to reveal complete cessation of bleeding and a small stable clot.

No rebleeding of the bite was noted at any time after hemostatic dressing removal. Both of the leech wounds were moderately pruritic for the subsequent 7 to 8 days. No evidence of infection was ever observed. Three days later, a dried dead leech was discovered on the inside of the patient's right pant leg, near the bite area (Figure 3).

\section{Discussion}

Leech bites are notorious for unstoppable bleeding. In one case series, the average time of bleeding was 10 hours, with an upper limit of a patient (who had normal laboratory test results) reportedly bleeding for 7 days. ${ }^{4}$ Although a single leech bite bleeding for hours to days will not typically cause significant harm, it may expose others to potentially infectious blood. In addition, multiple bites are common, and as many as 130 simultaneously bleeding leech bites on a single person have been reported in the literature; that patient presented in hemorrhagic shock and required 6 units of packed red blood cells and 8 units of fresh frozen plasma. ${ }^{6}$

After a leech latches, it may swallow as much as 10 times its own weight in blood, approximately $5 \mathrm{~mL}$ to 15 $\mathrm{mL}$ of blood per leech. ${ }^{7}$ Blood flows from the wound at a rate of $1 \mathrm{~mL} \cdot \mathrm{min}^{-1}$, both while the leech is attached

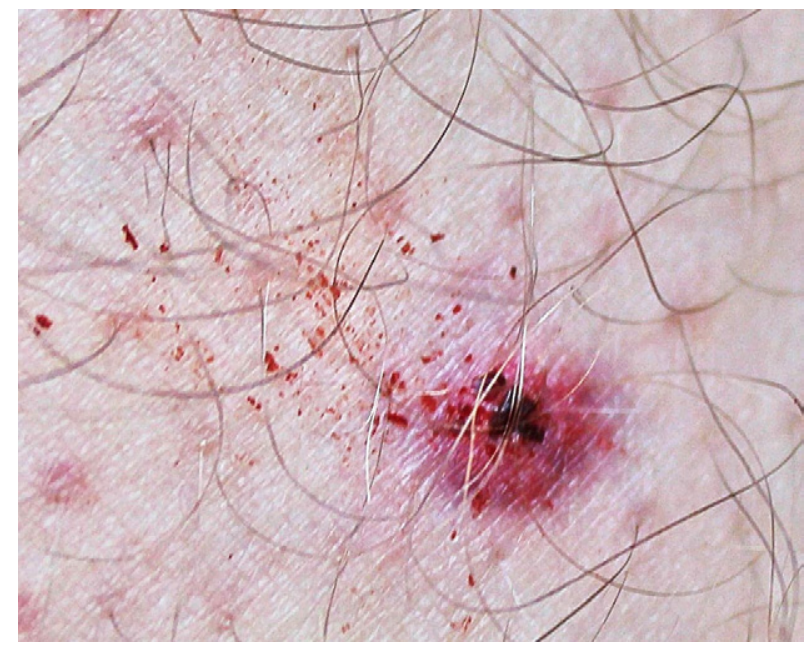

Figure 2. The Y-shaped wound typical of a leech bite. 


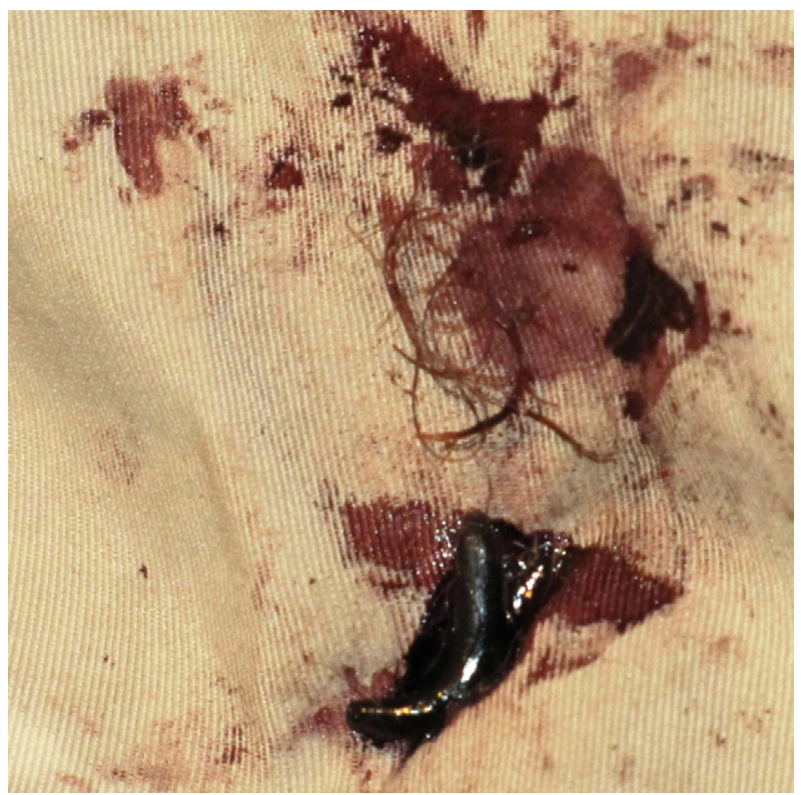

Figure 3. Presumed offending leech dried dead to inside of pant leg.

and after it has left. ${ }^{8}$ Thus, each active wound has the capability of losing $60 \mathrm{~mL}$ of blood in an hour. With numerous bites over many hours, that blood loss can become substantial. Typically, this amount of blood loss is well tolerated, but people living in leech-infested areas may suffer frequent bites, and occasionally patients will require blood transfusions. Cundall et $\mathrm{al}^{9}$ presented a case series of 3 patients with severe anemia, 1 of whom died as a result of leech-induced bleeding.

The majority of case reports related to nonmedicinal leeches reference bleeding wounds in places other than the skin. Leeches have been found on the cornea and in the nose, pharynx, larynx, esophagus, rectum, bladder, urethra, and vagina. These cases often were diagnosed late, after workups for tremendous amounts of bleeding from those sites. ${ }^{7,10-21}$ Although the topical treatments in this discussion are not appropriate for mucous membrane or intracavitary bleeding, it is prudent to consider leeches as an etiology of unusual bleeding when in endemic areas.

More than a dozen substances that modulate host responses have been found in leech saliva. Anesthetics in the saliva make for a painless bite. The anticoagulant hirudin is known to act as an antithrombin to promote bleeding. Calin is a potent antiplatelet agent. Inhibitors of factor Xa and the complement cascade are also present. Lastly, both histamine-like substances and acetylcholine function as vasodilators for continued bleeding. ${ }^{6,22}$ Leech bites do not usually cause alterations in measurable coagulation factors; however, rare reports to the contrary do exist. ${ }^{1,6,7,23}$
Leech bites are common worldwide, though it is unknown what proportion of the wounds will persistently bleed. Additionally, there is a paucity of published reports that addresses the problem of such hemorrhage when it occurs. The application of sterile gauze soaked with thrombin solution has been suggested, although no trials have been conducted. ${ }^{1,22}$ Electrocoagulation has been used successfully, but is only practical in the hospital setting. ${ }^{18}$ Suturing of lesions has not been recommended, as bleeding stems from the saliva's components, not from the open wound itself. The use of clotting factor replacement for persistent leech bite bleeding has been addressed only in a single case report. Fresh frozen plasma was administered to a patient with an intractable bleeding diathesis from 130 bites; the bleeding ceased on the same day of fresh frozen plasma use. ${ }^{6}$ Additionally, Bove et $\mathrm{al}^{24}$ found that DDAVP decreased bleeding in rabbits receiving hirudin infusions.

When in leech-prone areas, particularly in the wet season, it is important to do a thorough skin check after an activity. Much as ticks can hide in uncanny places and crevices, so can leeches. If an intact leech is discovered, do not attempt to aggressively remove it. The leech may rupture and leave behind its mouthparts, which may lead to infection and poor wound healing. The literature holds little objective guidance for the removal of leeches, but it is commonly held that they may be encouraged to release with the application of vinegar, alcohol, normal saline, salt, tea tree oil, eucalyptus oil, or anesthetic solutions. Additionally, a fingernail gently slid under the attached sucker while applying countertraction to the leech may release the pressure. ${ }^{1,7,10,22,25,26}$

After removal, irrigate with a copious amount of water to dilute the hirudin and other chemicals, as well as to decrease the possibility of infection. ${ }^{6}$ Attempt typical wound management for the bleeding lesion, such as direct pressure and elevation. If that fails, it has been suggested that a styptic pencil, topical thrombin on gauze, or an oxidized regenerated cellulose absorbable hemostat (such as Surgicel [Ethicon Inc, Neuchatel, Switzerland]) may be used to halt the bleeding. ${ }^{1,6,26}$ Given the mounting scientific evidence, and the success in this case, a hemostatic dressing applied to the wound is a reasonable solution as well.

Common complications from a leech bite include pruritus, rebleeding, local erythema, and irritation. Antibiotics are not recommended without objective evidence of wound infection. As for any potentially dirty wound, tetanus prophylaxis is indicated, if needed.

There is a growing body of literature related to hemostatic dressings, almost exclusively from military experience. No significant research has been conducted looking at these agents in the civilian prehospital realm. ${ }^{27}$ 
Although we rarely see the exsanguination-type bleeding in wilderness medicine for which the military has studied hemostatic dressings, many of the data can be extrapolated for our use. Hemostatic agents have been used by the military since 2003. The first to be deployed was QuikClot, which initially came in the form of granules that were poured into a bleeding wound. Since then, several companies have developed additional forms, from impregnated gauze pads and rolls to surgical sponges, to beads and powders. Virtually every soldier on the battlefield now carries some form of a hemostatic dressing. ${ }^{27-29}$

Hemostatic agents are popular in the military and useful in the wilderness setting for many of the same reasons. They seem to quickly stop otherwise uncontrollable bleeding (although no prospective trials in humans have been conducted). The dressings have an effective shelf life of more than 2 years, and are stable in extreme conditions. Lastly, they are light, portable, and relatively inexpensive for travelers. ${ }^{27,30,31}$

The accepted indications for use of a hemostatic agent are 1) bleeding uncontrolled by conventional means, such as direct pressure, elevation, and pressure points; and 2) bleeding in noncompressible areas like the neck, groin, or axilla. They are contraindicated for bleeding from mucous membranes or in body cavities. ${ }^{27,32,33}$ With QuikClot, the dressing should be applied directly over the wound, with pressure held for 3 minutes, or until the bleeding stops. It is also acceptable to initially apply pressure, and then wrap a tight bandage over the dressing to maintain pressure. ${ }^{32}$ In this leech bite case, the QuikClot was applied with direct pressure briefly, and then taped snugly over the wound.

These agents work to stop bleeding by 1 of 3 methods: 1) clotting factor concentration - by rapidly soaking up the water component of blood, clotting factors are concentrated at the site of the bleeding; QuikClot is the most common example; 2) mucoadhesion-these physically adhere to damaged tissues and vessels to seal the wound (HemCon bandage [HemCon Medical Technologies Inc, Portland, OR], which is made from the shells of marine arthropods, is the best known); and 3) procoagulant supplementation-dressings such as the kaolin-based Combat Gauze (Z-Medica) provide additional factors that promote clotting or initiate the clotting cascade. ${ }^{27,30,31}$

The military has a multitude of dressings at its disposal. ${ }^{27,29-31}$ For civilians, very few are available over the counter. QuikClot is the most common and inexpensive; it can be found online and at many outdoor stores in the United States. It comes in a variety of forms and sizes, from $2 \times 2$-inch gauze to thick abdominal pads to rolls of gauze. HemCon and Celox (Medtrade Prod- ucts Ltd, Crewe, UK) have received Food and Drug Administration approval for everyday use, although they currently can only be purchased through tactical and medical supply sources. ${ }^{32,33}$ A $4 \times 4$-inch QuikClot gauze pad was used in Nepal, as it was the only hemostatic dressing available to the team (in the patient's personal first aid kit).

This case, in light of the available literature, suggests that hemostatic dressings may be effective for bleeding leech bites, and should be included in the medical kits of those visiting endemic areas. The product itself is widely available in the United States, weighs next to nothing, and does not expire. The potential downside is price, as the dressings currently cost anywhere from $\$ 10$ to $\$ 150$ (US dollars) each. For an expedition physician or wellequipped tourist, the obvious benefit will greatly outweigh the cost. However, in the developing world, where leech bites are most common and severe, such a price tag may still be prohibitive, and limit availability of these dressings. For the moment, there is no obvious way to cut the cost. A treatment is life-saving only if it is affordable enough to be readily available. Therefore, medical personnel in these developing countries are not likely to utilize the dressings for persons afflicted in their community. It may be feasible, however, for clinics and hospitals in endemic areas to stock hemostatic dressings (particularly during the peak wet season) with the help of donations or grants.

\section{Conclusions}

Leech bites are a common occurrence throughout the world, although rarely life-threatening. These wounds may bleed persistently for hours to days afterward. There are anecdotal treatments but no evidence in the literature that addresses the care of these wounds. This case report demonstrates the first reported use of QuikClot for successfully ending leech wound bleeding. Along with common sense wound care, hemostatic dressings are a reasonable adjunct for the treatment of bleeding leech bites. Given this is a single case, additional study is needed to confirm the value of hemostatic agents for this purpose, and to determine how to provide effective and affordable agents to endemic areas in the developing world.

\section{Acknowledgments}

The author would like to thank Drs David Wachter and Mark Hauswald for making the leech attack possible, and encouraging the creation of this report. The author has no financial interests in any of the products discussed. 


\section{References}

1. Ikizceli I, Avsarogullari L, Sozuer E, Yurumez Y, Akdur O. Bleeding due to a medicinal leech bite. Emerg Med J. 2005;22:458-460.

2. Munshi Y, Ara I, Rafique H, Ahmad Z. Leeching in the history-a review. Pak J Biol Sci. 2008;11:1650-1653.

3. Vera C, Blu A, Torres M. Leeches today and yesterday present parasites [in Spanish]. Rev Chilena Infectol. 2005;22:32-37.

4. Munro R, Hechtel FO, Sawyer RT. Sustained bleeding after a leech bite in the absence of hirudin. Thromb Haemost. 1989;61:366-369.

5. Introduction to Global Health: Nepal. General overview. Available at: http://web.mac.com/drwachter/iWeb/ Nepal\%20Page/Front\%20Page.html. Accessed April 25, 2011.

6. Kose A, Zengin S, Kose B, et al. Leech bites: massive bleeding, coagulation profile disorders, and severe anemia. Am J Emerg Med. 2008;26:1067.e3-1067.e6.

7. Saha PK, Roy S, Bhattacharya D, Mukherjee P, Naskar T, Bhuiya A. Leech bite: a rare gynecologic emergency. Med Gen Med. 2005;7:73.

8. Haycox CL, Odland PB, Coltrera MD, Raugi GJ. Indications and complications of medicinal leech therapy. J Am Acad Dermatol. 1995;33:1053-1055.

9. Cundall DB, Whitehead SM, Hechtel FO. Severe anaemia and death due to the pharyngeal leech Myxobdella africana. Trans R Soc Trop Med Hyg. 1986;80:940-944.

10. Dey R, Dey S. Ocular leech infestation. Arch Iran Med. 2010;13:440-442.

11. Ghimire A, Acharya A. Unusual cause of unilateral epistaxis: nasal leech infestation. J Nepal Med Assoc. 2008;47:38-40.

12. Jafari Rouhi AH, Vegari S, Vahdati SS, Porhosein D, Davarnia G. Nasopharyngeal bleeding due to leech bites in a 9 month old infant. Indian J Pediatr. 2010;77:573-574.

13. Chen WC, Chien CY, Yang CH, Li JH, Hwang CF. Nasal leech infestation: report of seven leeches and literature review. Eur Arch Otorhinolaryngol. 2010;267:1225-1229.

14. Bulent A, Ilknur O, Beray S, Tulin C, Ulku T, Yildiz D. An unusual case of hemoptysis in a child: live leech in the posterior pharynx. Trop Biomed. 2010;27:208-210.

15. Mohammad Y, Rostum M, Dubaybo BA. Laryngeal hirudiniasis: an unusual cause of airway obstruction and hemoptysis. Pediatr Pulmonol. 2002;33:224-226.

16. Pandey CK, Sharma R, Baronia A, Agarwal A, Singh N. An unusual cause of respiratory distress: live leech in the larynx. Anesth Analg. 2000;90:1227-1228.

17. Krüger C, Malleyeck I, Olsen $\mathrm{OH}$. Aquatic leech infestation: a rare cause of severe anaemia in an adolescent Tanzanian girl. Eur J Pediatr. 2004;163:297-299.
18. Raj SM, Radzi M, Tee MH. Severe rectal bleeding due to leech bite. Am J Gastroenterol. 2000;95:1607.

19. Al B, Yenen ME, Aldemir M. Rectal bleeding due to leech bite: a case report. Turkish J Trauma Emerg Surg. 2011; 17:83-86.

20. Ahmad R, Baharuddin KA, Zaidin H, Mohidin MA, Kheng $\mathrm{CP}$, Sidek N. An unusual case of urethral hirudiniasis. Southeast Asian J Trop Med Public Health. 2008;39: 319-323.

21. Paul AK, Islam N. Vesical hirudiniasis: an unusual cause of bleeding from the urethra. J Ultrasound Med. 2005;24: 1731-1733.

22. Adams SL. The emergency management of a medicinal leech bite. Ann Emerg Med. 1989;18:316-319.

23. Kumar N, Mohindra R, Mohan B, Wander GS. Gastrointestinal bleeding after leeching in a patient on aspirin therapy. Indian J Gastroenterol. 2005;24:170.

24. Bove CM, Casey B, Marder VJ. DDAVP reduces bleeding during continued hirudin administration in the rabbit. Thromb Haemost. 1996;75:471-475.

25. Lawton G, Granville-Chapman J, Parker PJ. Novel haemostatic dressings. J R Army Med Corps. 2009;155: 309-314.

26. Mazzorana V, Maeyenas E. Aquatic skin disorders (leeches). In: Auerbach PS, ed. Wilderness Medicine. 5th ed. St. Louis, MO: Mosby, Inc; 2007:1769-1770.

27. Granville-Chapman J, Jacobs N, Midwinter MJ. Prehospital haemostatic dressings: a systematic review. Injury. 2011;42:447-459.

28. Pusateri AE, Holcomb JB, Kheirabadi BS, Alam HB, Wade CE, Ryan KL. Making sense of the preclinical literature on advanced hemostatic products. J Trauma. 2006;60:674-682.

29. Gordy SD, Rhee P, Schreiber MA. Military applications of novel hemostatic devices. Expert Rev Med Devices. 2011; 8:41-47.

30. Kheirabadi B. Evaluation of topical hemostatic agents for combat wound treatment. US Army Med Dep J. 2011;AprJun:25-37.

31. Ahuja N, Ostomel TA, Rhee P, et al. Testing of modified zeolite hemostatic dressings in a large animal model of lethal groin injury. J Trauma. 2006;61:1312-1320.

32. Z-Medica. Healthcare product portfolio. Available at: http://www.z-medica.com/healthcare/home.aspx. Accessed August 30, 2011.

33. HemCon. Emergency \& trauma solutions. Available at: http:// www.hemcon.com/solutions/emergencytraumasolutions. aspx. Accessed August 30, 2011. 